\title{
Thermodynamic Modelling of Precious Metals Alloys
}

\author{
Bernd Kempf \\ Degussa AG, Geschäftsbereich Edelmetalle, Forschunghung und Entwicklung, Hanau, Germany \\ and Siegfried Schmauder \\ $\overline{\text { Staatliche Materialprüfungsanstalt, Universität Stuttgart, Germany }}$
}

\begin{abstract}
The alloy system Au-Ag-Pd-Pt-Sn is described with the help of the thermodynamic software 'Chemsage' and a specially modelled dataset. Calculations on the stability of precipitated phases show good agreement with experimental results from hardness tests and metallography and thereby provide a better understanding of the observed material properties. The use of such modelling provides an efficient tool for faster and more direct development of precious metal alloys.
\end{abstract}

Gold alloys are frequently used in jewellery and dentistry. For jewellery the main reasons are the intrinsic value of gold, its beauty and its unique resistance to tarnish and corrosion (1). For dentistry the main reasons are, apart from the high corrosion resistance and hence the extraordinary biocompatibility, the wide variety of mechanical properties which can be adjusted by variations in the alloy compositions (2). Wide ranging applications in these fields, with continuously changing demands on the alloy properties due to new fashion trends or new medical or technical requirements, is a reason for ongoing research and development to create new alloys with better or special properties.

Although calculation methods are not new in science, optimization of precious metal alloys in industrial practice has to date been carried out in a rather empirical way by melting and testing numerous experimental alloys. More recently, commercially available thermodynamic software such as 'Chemsage' $(3,4)$ has allowed 'alloy modelling' with specially modelled datasets (5) which are useful for the skilled practical engineer in industry. For example, it is possible to calculate the stability of precipitated phases, which are responsible for the hardening behaviour of alloys. This leads to a deeper understanding of the complex hardening mechanisms and hence allows a reduction in experimental work. In this article we consider the potential of thermodynamic modelling and the interpretation of the calculated stabilities of precipitating phases in relation to experimental results in hardness testing and metallography with the help of five alloy compositions in the system Au-Ag-Pt-Pd-Sn.

\section{ALLOY MODIFICATIONS AS A FUNCTION OF ELEMENT NUMBER AND CONCENTRATION STEPS}

A mathematical approach to the number of alloy modifications theoretically possible, resulting from variations in the number of components and their concentrations, leads to an enormous number of possible alloys if the number of elements is increased and the concentration steps are decreased to values typical of those used in current alloy developments.

In a ternary system like gold - silver - copper (Figure 1) it is still rather easy to calculate how many alloy modifications are possible, if one allows, for example, concentration steps of $20 \%$. This results in 21 different alloys, as can easily be seen in Figure 1. For a larger number of elements and smaller concentration steps the calculation of possible alloy modifications has to be performed in the following way:

The number of alloy modifications $(\mathrm{m})$ is given (6) by the equation: 


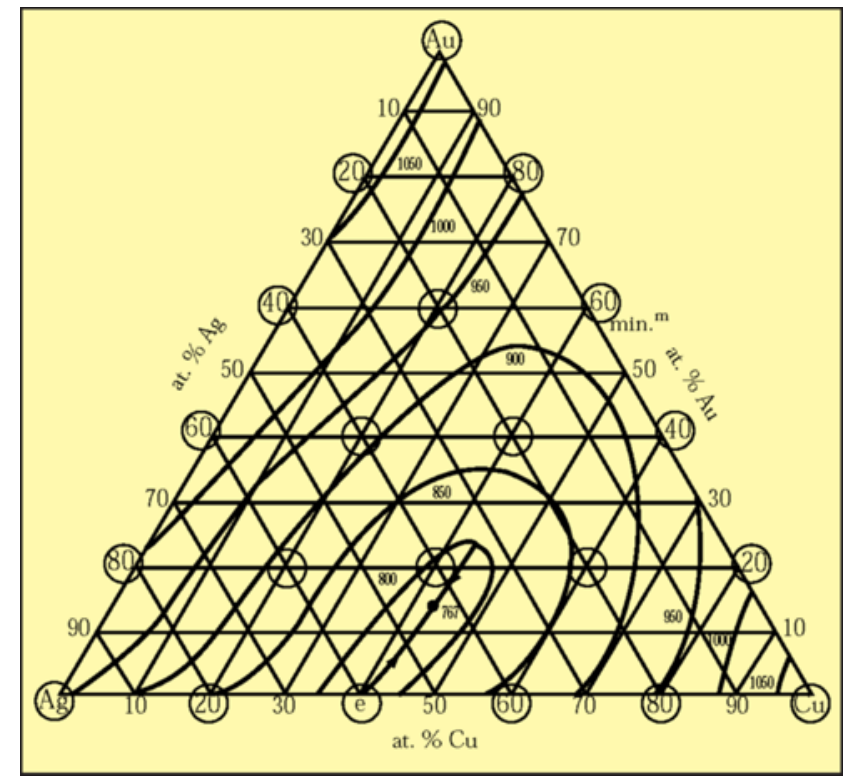

Figure 1 Ternary system $A u-A g-C u$. The circles represent the possible alloy modifications for concentration steps of $20 \%$

$$
m=\left(\begin{array}{c}
n+i-1 \\
i
\end{array}\right)\left(\begin{array}{c}
n+i-1 \\
n-1
\end{array}\right)
$$

where $n=$ number of elements $E_{1}, E_{2}, \ldots, E_{n}$ in the alloy,

$\mathrm{i}=100 / \mathrm{c}=$ number of intervals into which the presence of each element in the alloy may be subdivided and

$\mathrm{c}=\mathrm{c}_{1}=\mathrm{c}_{2}=\ldots=\mathrm{c}_{\mathrm{n}}=$ concentration steps,

identical for all $\mathrm{n}$ elements

(see Table 1)

Table 1 Number of possible alloy modifications as a function of number of elements and concentration steps for a few examples

$\begin{array}{ccr}\begin{array}{l}\text { number of } \\ \text { elements }(\mathbf{n})\end{array} & \begin{array}{l}\text { concentration } \\ \text { steps in \% (c) }\end{array} & \begin{array}{r}\text { number of alloy } \\ \text { modifications (m) }\end{array} \\ 3 & 20 & 21 \\ 3 & 1 & 5151 \\ 6 & 20 & 252 \\ 6 & 1 & 96,560,646 \\ 10 & 20 & 2002 \\ 10 & 10 & 92378 \\ 10 & 5 & 10,015,005 \\ 10 & 1 & 4,263,421,511,271\end{array}$

To verify this equation, a simple permutational argument is applied. Any sequence of $i$ elements given in an ordered way as $E_{j 1}, E_{j 2}, \ldots, E_{j 1}$ with $j_{k+1} \geq j_{k}$ is called a combination with repetition of length i over $n$ elements.

In the following an example is given for $n=4$ and $i=3$ in lexicographic order:

$\mathrm{E}_{1} \mathrm{E}_{1} \mathrm{E}_{1} \quad \mathrm{E}_{1} \mathrm{E}_{2} \mathrm{E}_{2} \quad \mathrm{E}_{1} \mathrm{E}_{3} \mathrm{E}_{4} \quad \mathrm{E}_{2} \mathrm{E}_{2} \mathrm{E}_{4} \quad \mathrm{E}_{3} \mathrm{E}_{3} \mathrm{E}_{3}$ $E_{1} E_{1} E_{2} \quad E_{1} E_{2} E_{3} \quad E_{1} E_{4} E_{4} \quad E_{2} E_{3} E_{3} \quad E_{3} E_{3} E_{4}$

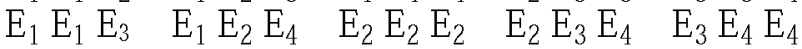
$\mathrm{E}_{1} \mathrm{E}_{1} \mathrm{E}_{4} \quad \mathrm{E}_{1} \mathrm{E}_{3} \mathrm{E}_{3} \quad \mathrm{E}_{2} \mathrm{E}_{2} \mathrm{E}_{3} \quad \mathrm{E}_{2} \mathrm{E}_{4} \mathrm{E}_{4} \quad \mathrm{E}_{4} \mathrm{E}_{4} \mathrm{E}_{4}$

An equivalent representation of these figures is given by a sequence of 0 's and 1 's, where the 1 's correspond to the occurrence of an element and the 0 's mark the transition to the next element. This is shown by the following examples of the above triplets of elements.

$$
\begin{aligned}
& \mathrm{E}_{1} \mathrm{E}_{1} \mathrm{E}_{1}=111000 \\
& \mathrm{E}_{1} \mathrm{E}_{3} \mathrm{E}_{3}=100110 \\
& \mathrm{E}_{2} \mathrm{E}_{4} \mathrm{E}_{4}=010011 \\
& \mathrm{E}_{3} \mathrm{E}_{4} \mathrm{E}_{4}=001011
\end{aligned}
$$

These sequences of $n-10$ 's and i l's are called the $m$ permutations with repetition of length $n+i-1$, where according to basic permutation theory:

$$
m=\left(\begin{array}{c}
n+i-1 \\
i
\end{array}\right)=\frac{(n+i-1) !}{(n-1) ! i !}
$$

eg

$$
m=\left(\begin{array}{c}
3+4-1 \\
3
\end{array}\right)=\left(\begin{array}{l}
6 \\
3
\end{array}\right)=-\frac{6 !}{3 ! 3} T=20 \text { in the above example. }
$$

An elegant and easily understandable presentation of this mathematical calculation can be found in Reference 7 .

In Table 1 are listed some examples of the possible number of alloy modifications for different numbers of alloy components and concentration steps.

For 10 elements the number of possible alloy modifications at high concentration steps is still rather limited, because only some of the 10 elements can be in the alloy at the same time. But with smaller steps (every metallurgist knows that steps of even less than $1 \%$ can have very significant effects), the number of possible alloys increases rather dramatically. Hence, any means whereby experimental work can be reduced is very desirable.

Many of these possible alloy modifications can of course also be excluded simply as a result of qualitative empirical metallurgical knowledge. But the examples will show that the calculated phase stabilities, in combination with the experimental results of a few alloys, can give a deep insight into the hardening 


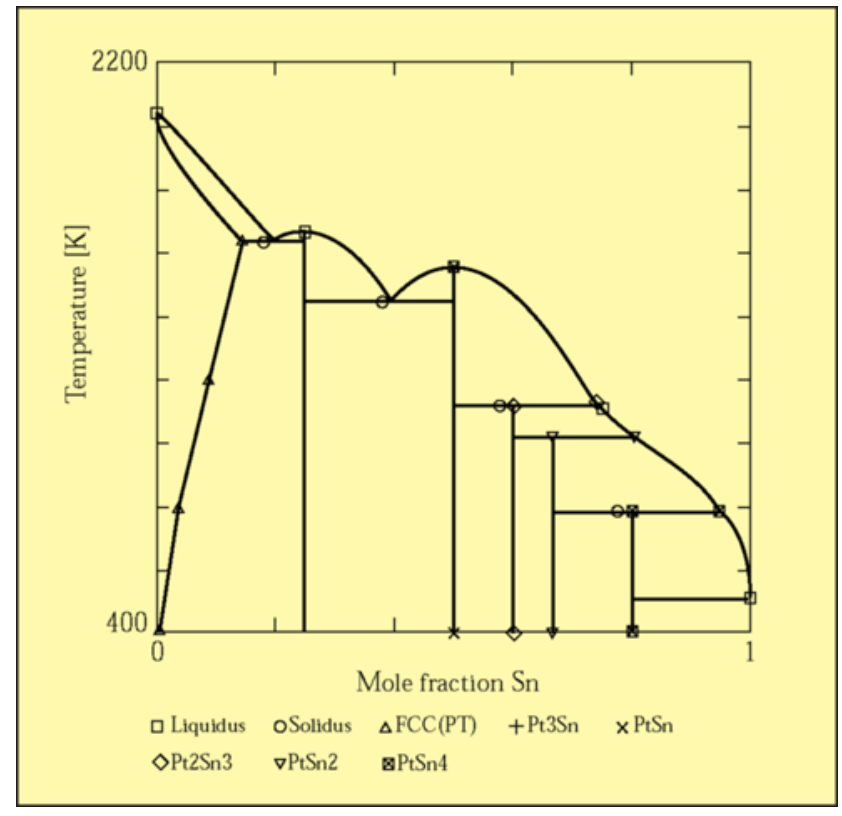

Figure 2a Calculated phase diagram for the system Pt-Sn, based on the thermochemical dataset

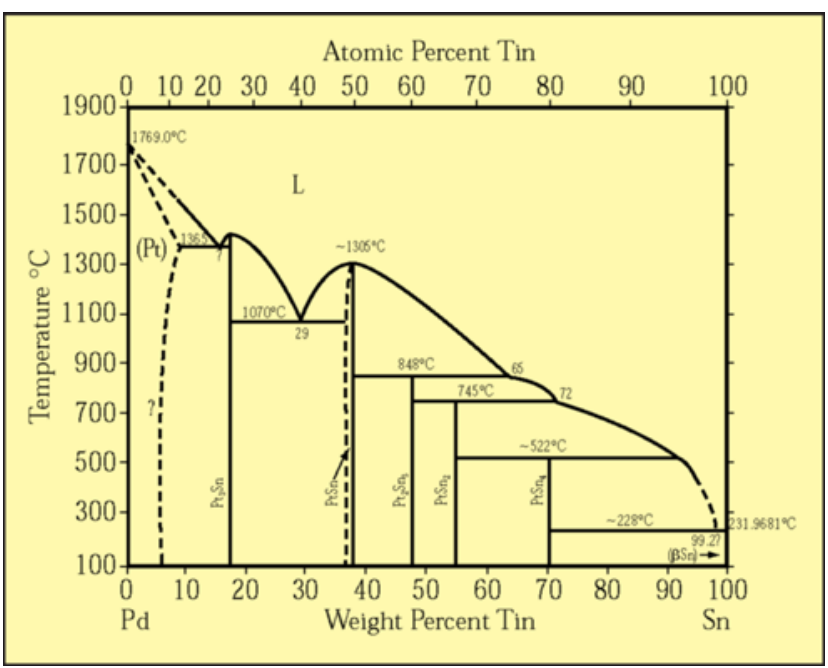

Figure 2b Experimental phase diagram for the system Pt-Sn, from reference 10

mechanisms, enabling the metallurgist to plan further experiments in a highly focussed manner.

\section{THERMODYNAMIC MODELLING OF THE Au-Ag-Pd-Pt-Sn ALLOY SYSTEM}

The model used for the thermodynamic calculations is very similar to the model described in Reference 5. Additionally the element silver is included. The model

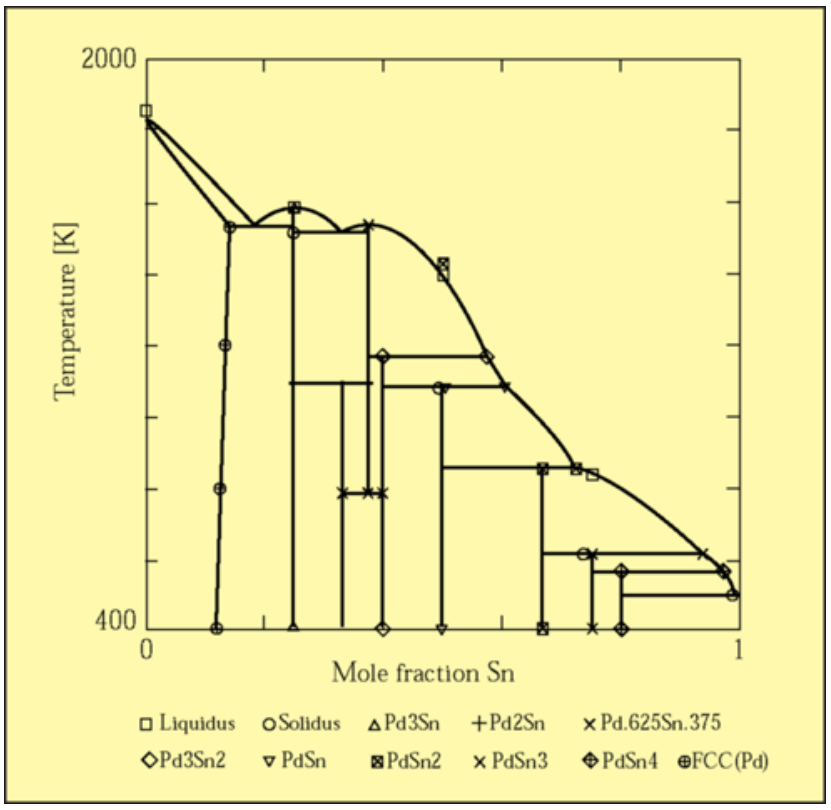

Figure 2c Calculated phase diagram for the system $\mathrm{Pd}-\mathrm{Sn}$, based on the thermochemical dataset

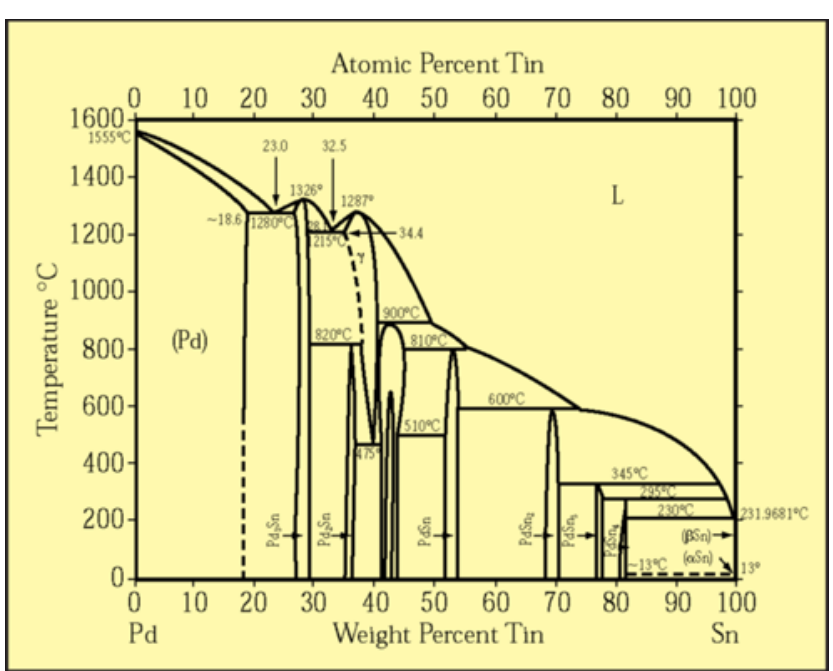

Figure 2d Experimental phase diagram for the system Pd-Sn, from reference 10

is based on the binary sub-systems $\mathrm{Au}-\mathrm{Ag}, \mathrm{Au}-\mathrm{Pd}$, Au-Pt, Au-Sn, Ag-Pd, Ag-Pt, Ag-Sn, Pd-Pt, Pd-Sn, $\mathrm{Pt}-\mathrm{Sn}$ and is optimized for the gold-rich region. For the calculations of the phase stabilities the commercially available software 'Chemsage' was used, which provides an efficient minimization program for the Gibb's energy. The modelled data set consists of the gas phase, a liquid phase, solid solutions and all the known solid, intermetallic phases, which were modelled as stoichiometric phases. In Table 2 all the phases of the modelled system are listed. The modelled 
Table 2 List of all phases used in the modelled system (a) : for modelling the miscibility gap in the Au-Pt-system, this phase is used twice in the calculations; RKMP: Redlich Kister Muggiano Polynom; IDMX. Ideal Mixture)

Phases
Gas
Liquid phase
Solid Solution
Solid Solution
Solid Solution
Intermet. Phase
Intermet. Phase
Intermet. Phase
Intermet. Phase
Intermet. Phase
Intermet. Phase
Intermet. Phase
Intermet. Phase
Intermet. Phase
Intermet. Phase
Intermet. Phase
Intermet. Phase
Intermet. Phase
Intermet. Phase
Intermet. Phase
Intermet. Phase
Intermet. Phase
Intermet. Phase

\begin{tabular}{|c|c|}
\hline Components & Structure, Stoichiometry \\
\hline $\mathrm{Ag}, \mathrm{Au}, \mathrm{Pt}, \mathrm{Pd}, \mathrm{Sn}$ & - \\
\hline $\mathrm{Ag}, \mathrm{Au}, \mathrm{Pd}, \mathrm{Pt}, \mathrm{Sn}$ & - \\
\hline $\mathrm{Ag}, \mathrm{Au}, \mathrm{Pd}, \mathrm{Pt}, \mathrm{Sn}$ & FCC A2 \\
\hline $\mathrm{Ag}, \mathrm{Au}, \mathrm{Pd}, \mathrm{Pt}, \mathrm{Sn}$ & $\mathrm{BCC} A 2$ \\
\hline $\mathrm{Ag}, \mathrm{Au}, \mathrm{Pd}, \mathrm{Pt} \mathrm{Sn}$ & HCP A3 \\
\hline $\mathrm{Ag}, \mathrm{Sn}$ & $\mathrm{Ag}_{3} \mathrm{Sn}$ \\
\hline $\mathrm{Au}, \mathrm{Sn}$ & $\beta$ \\
\hline $\mathrm{Au}, \mathrm{Sn}$ & $\mathrm{AuSn}$ \\
\hline $\mathrm{Au}, \mathrm{Sn}$ & $\mathrm{Au} \mathrm{Sn_{2 }}$ \\
\hline $\mathrm{Au}, \mathrm{Sn}$ & $\mathrm{Au} \mathrm{Sn}_{4}$ \\
\hline $\mathrm{Pd}, \mathrm{Sn}$ & $\mathrm{Pd}_{3} \mathrm{Sn}$ \\
\hline $\mathrm{Pd}, \mathrm{Sn}$ & $\mathrm{Pd}_{2} \mathrm{Sn}$ \\
\hline $\mathrm{Pd}, \mathrm{Sn}$ & $\mathrm{Pd}_{5} \mathrm{Sn}_{3}$ \\
\hline $\mathrm{Pd}, \mathrm{Sn}$ & $\mathrm{Pd}_{3} \mathrm{Sn}_{2}$ \\
\hline $\mathrm{Pd}, \mathrm{Sn}$ & $\mathrm{Pd} \mathrm{Sn}$ \\
\hline $\mathrm{Pd}, \mathrm{Sn}$ & $\mathrm{Pd} \mathrm{Sn_{2 }}$ \\
\hline $\mathrm{Pd}, \mathrm{Sn}$ & $\mathrm{Pd} \mathrm{Sn_{3 }}$ \\
\hline $\mathrm{Pd}, \mathrm{Sn}$ & $\mathrm{Pd} \mathrm{Sn}_{4}$ \\
\hline $\mathrm{Pt}, \mathrm{Sn}$ & $\mathrm{Pt}_{3} \mathrm{Sn}$ \\
\hline $\mathrm{Pt}, \mathrm{Sn}$ & Pt Sn \\
\hline $\mathrm{Pt}, \mathrm{Sn}$ & $\mathrm{Pt}_{2} \mathrm{Sn}_{3}$ \\
\hline $\mathrm{Pt}, \mathrm{Sn}$ & $\mathrm{Pt} \mathrm{Sn}_{2}$ \\
\hline $\mathrm{Pt}, \mathrm{Sn}$ & $\mathrm{Pt} \mathrm{Sn}_{4}$ \\
\hline
\end{tabular}

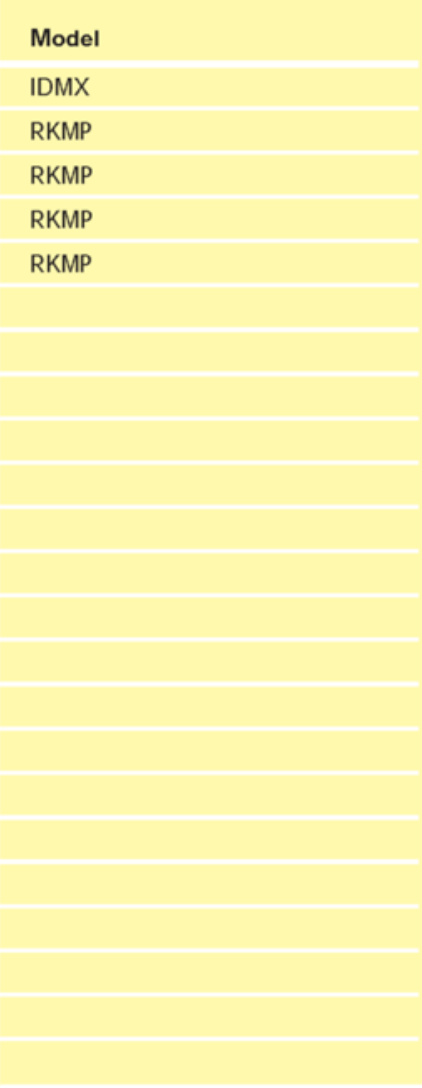

dataset was delivered by the GTT company. The thermodynamic data used are taken from the literature and were evaluated for this work.

The quality of the model can be checked in a first step by comparing calculated with experimental phase diagrams. While for simple systems like Au-Ag, a very good agreement can be achieved, some restrictions must be accepted for more complex diagrams like Pt$\mathrm{Sn}$ and $\mathrm{Pd}-\mathrm{Sn}$. In Figures 2a - 2d these experimental and calculated diagrams are given as an example. In spite of these simplifications, this model already allows useful interpretations of experimental results.

It is necessary to keep in mind that ternary and still higher order phases and interactions are not yet considered in this model. The 'Chemsage' software allows, in principle, the modelling of higher order effects, but there is usually no complete information available in the literature on the higher order effects of multicomponent alloys. This is the case for the alloys under consideration here. Consequently, the only way to check the reliability of the 'binary-based model', is via a series of key experiments as undertaken in this work. Complete new ternary phases will of course
Table 3 Composition of test alloys in wt\%

$\begin{array}{cccccc}\begin{array}{c}\text { Alloy } \\ \text { No. }\end{array} & \text { Au } & \text { Ag } & \text { Pd } & \text { Pt } & \text { Sn } \\ 1 & 82 & - & - & 16 & 2 \\ 2 & 82 & - & 15 & - & 3 \\ 3 & 63 & 20 & - & 15 & 2 \\ 4 & 62 & 20 & 15 & - & 3 \\ 5 & 80.4 & - & 13.5 & 4 & 2.1\end{array}$

usually influence the alloy properties much more strongly than, for example, a limited solubility of a third component in a binary stoichiometric intermetallic phase. In this work the experiments will show that already the binary data alone can be useful for interpreting the multicomponent alloy system investigated here.

Work still in progress shows that the additional modelling of higher order effects leads to a still more consistent picture of calculations and experiments, whereas the basic tendencies are not altered $(8,9)$. 
Table 4 Results of hardness testing and metallographic investigations

$\begin{array}{cc}\text { Alloy No } & \begin{array}{c}\text { as cast condition } \\ \text { [Vickers hardness] }\end{array} \\ 1 & 85 \\ 2 & 200 \\ 3 & 87 \\ 4 & 138 \\ 5 & 175\end{array}$

\section{EXPERIMENTS AND THERMO- DYNAMIC CALCULATIONS}

In order to compare experimental results with thermodynamic stability calculations the alloys given in Table 3 were melted and investigated. Small additions of grain refiners are omitted from the composition table.

The hardness of the alloys was measured both in the 'as cast' and the annealed condition (ie $10 \mathrm{~min}$ at $950^{\circ} \mathrm{C}$, air cooled). The metallographic investigations were carried out using light microscopy and by microprobe analysis of secondary phases. The results are presented in Table 4.

The alloys show significantly different behaviour. High hardness values correlate with single-phase alloys, while low hardness values are characteristic of a twophase structure. In Figures $3 \mathrm{a}$ and $3 \mathrm{~b}$ the micrographs of Alloys 3 and 4 are given. Alloy 4 , which shows only traces of a second phase, has medium hardness values. Microprobe analysis reveals that the secondary phase has a composition of about Pt75Sn25 (at\%) in the case of Alloys 1 and 3 and of about Pd75Sn25 (at\%) in the case of Alloy 4.

The thermodynamic calculations are presented in Figures 4 a - e. The Figures give the calculated amounts of stable phases, related to $100 \mathrm{~g}$ of alloy as a function of temperature. The calculations were done in temperature steps of $100^{\circ} \mathrm{C}$. Using the program option 'one-dimensional-phase-mapping' temperatures may be

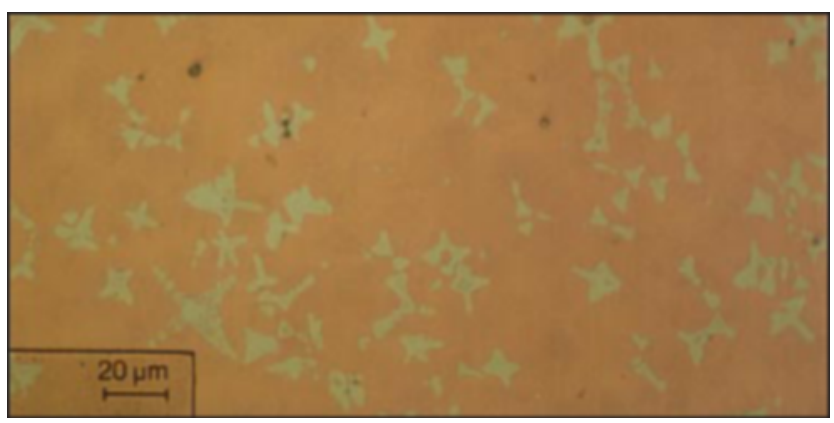

Figure 3a Secondary phase in Alloy 3

annealed condition
[Vickers hardness]
69
231
76
177
215

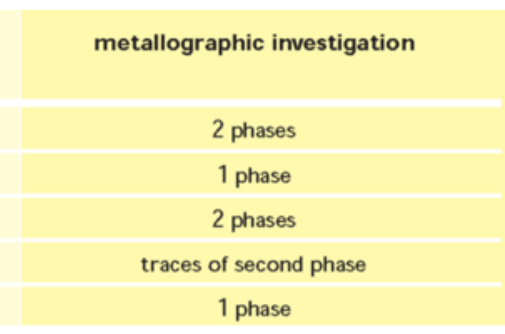

calculated when a phase is forming or disappearing. Apart from the solution phases 'FCC A1' and 'Liquid', the stoichiometric phases $\mathrm{Pt}_{3} \mathrm{Sn}$ and $\mathrm{Pd}_{3} \mathrm{Sn}$ are stable in some temperature ranges. In Figures $4 \mathrm{a}$ and $\mathrm{c}$ the FCC Al phase occurs twice. This symbolises the miscibility gap in the Au-Pt-system, which consists of two FCC A1 phases with different compositions. Due to the strong interaction between $\mathrm{Pt}$ and $\mathrm{Sn}$, this miscibility gap is shifted to lower temperatures in comparison to the binary system.

\section{DISCUSSION}

The results of the thermodynamic calculations show good consistency with the experimental results. In all alloys the dominating phase is the 'FCC A1' solid solution. At high temperatures the liquid-phase also remains stable. Only for Alloy 5 is the melting range so high that in the chosen temperature range no liquid phase is stable.

Alloys 1 and 3 already have a stable secondary phase of the stoichiometric composition $\mathrm{Pt}_{3} \mathrm{Sn}$ at high temperatures. Its stability range reaches up to the melting range of the alloys, whereas in the case of the silver-containing Alloy 3, the stability seems a little higher still. This means that during the solidification of these alloys a co-solidification of matrix phase and secondary phase will take place. Surface energy effects and high diffusion rates at the high temperatures will result in a coarse secondary phase which cannot have

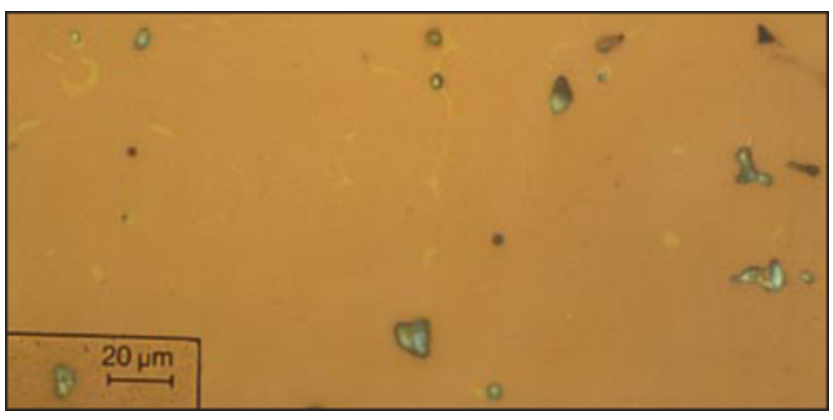

Figure 3b Traces of secondary phase in Alloy 4 
strong hardening effects. The microprobe analysis of the secondary phase indicates a composition for Pt:Sn of ca 3:1, as calculated. The low hardness values correspond to those expected.

The calculation for Alloy 2 shows the stoichiometric intermetallic phase $\mathrm{Pd}_{3} \mathrm{Sn}$ as a secondary stable phase. But in contrast to the Alloys 1 and 3 , this phase first becomes stable at temperatures below $700^{\circ} \mathrm{C}$. This results in a finely dispersed secondary phase, which is so fine that the second phase can only be detected in a transmission electron microscope. Figure 5 shows a dark field image of Alloy 2 after an age hardening process, in which the ordered phase $\mathrm{Pd}_{3} \mathrm{Sn}$ shows a particle size of only about $50 \mathrm{~nm}$.

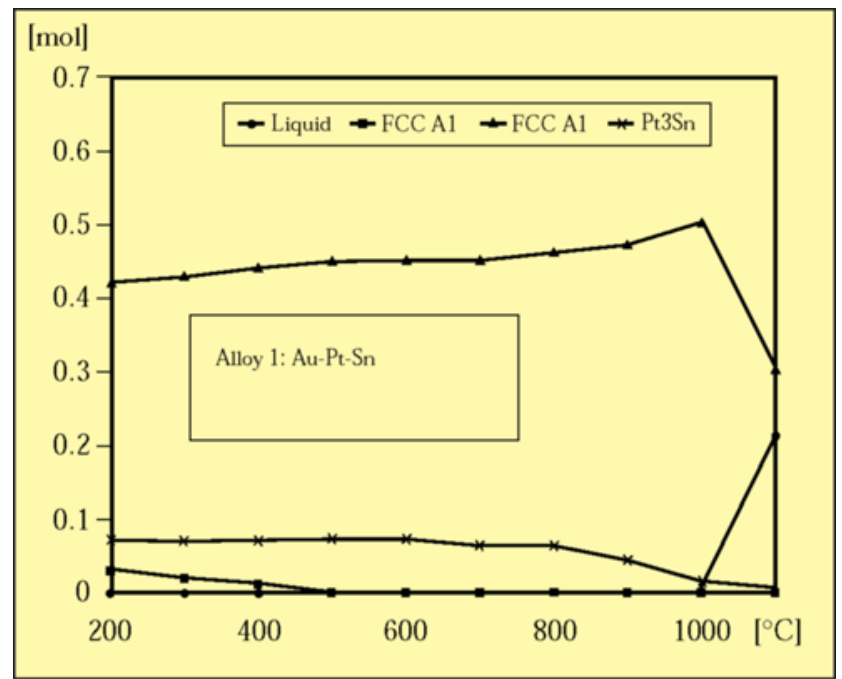

Figure 4a Calculated amounts of stable phases as a function of temperature for Alloy 1

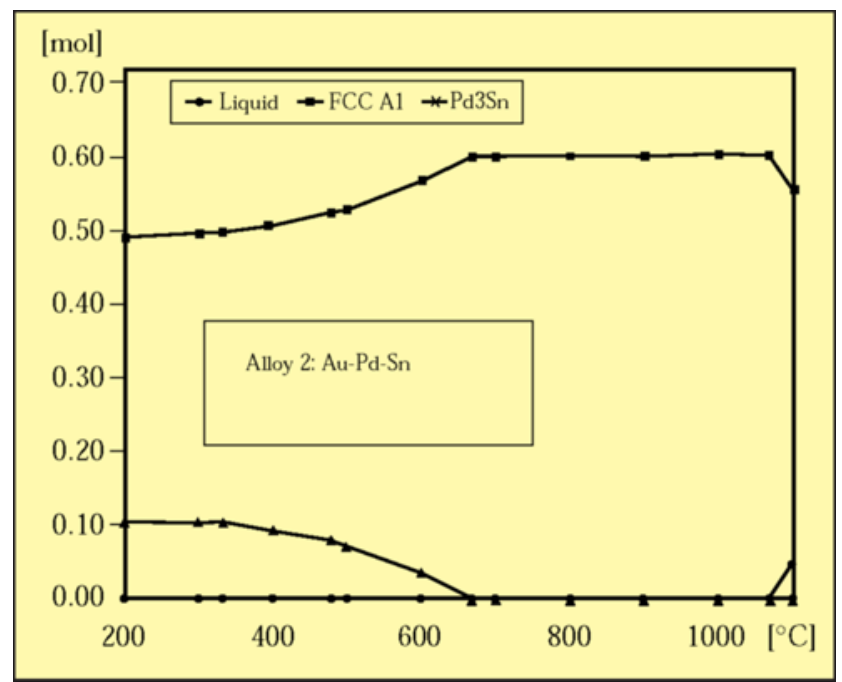

Figure $4 \mathrm{~b}$ Calculated amounts of stable phases as a function of temperature for Alloy 2
On the other hand, this finely dispersed second phase results in a significant hardening effect.

In Alloy 4, the addition of silver leads to an increased stability of the $\mathrm{Pd}_{3} \mathrm{Sn}$ phase. Traces of the second phase can be detected in the optical microscope and the hardness values do not reach the values of Alloys 2 and 5.

In Alloy 5, both $\mathrm{Pd}$ and $\mathrm{Pt}$ are present and the calculation indicates that they both form stable precipitates at rather low temperatures, resulting again in high hardness values and a single phase structure in the light microscope. In reality, $\mathrm{Pd}$ and $\mathrm{Pt}$ are able to form a ternary phase of formula $(\mathrm{Pd}, \mathrm{Pt})_{3} \mathrm{Sn}$ with $\mathrm{Sn}$. This has a similar stability to the binary phases. A

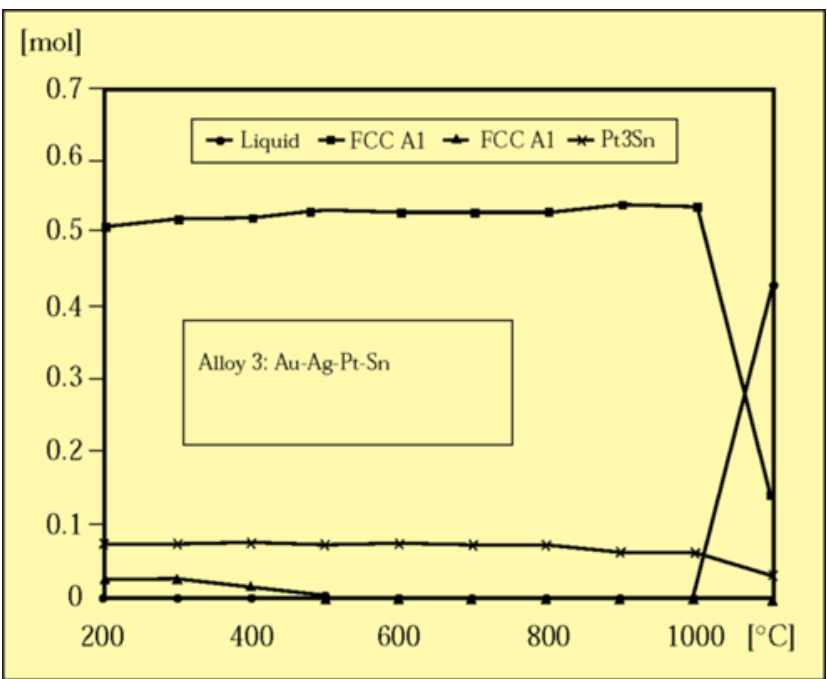

Figure 4c Calculated amounts of stable phases as a function of temperature for Alloy 3

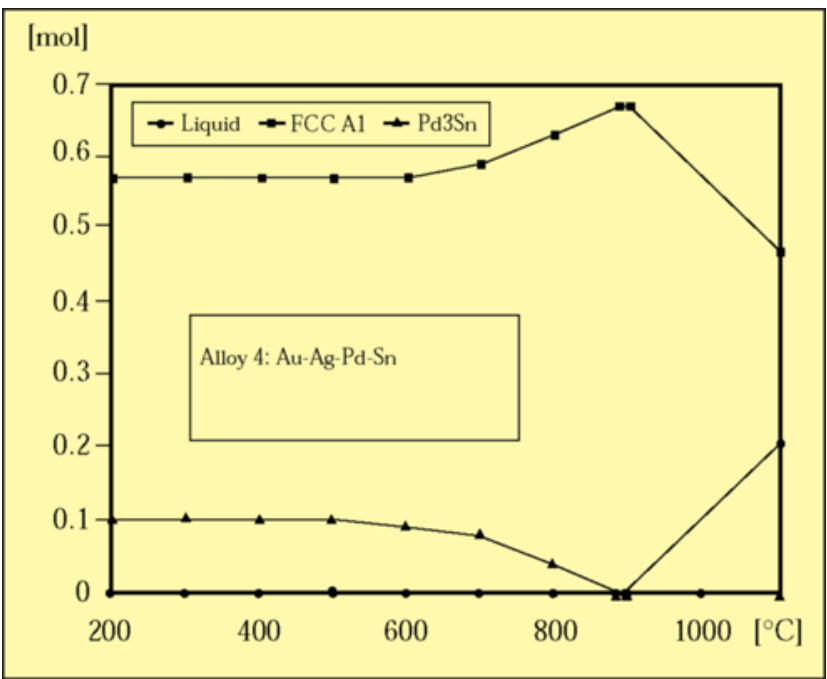

Figure 4d Calculated amounts of stable phases as a function of temperature for Alloy 4 


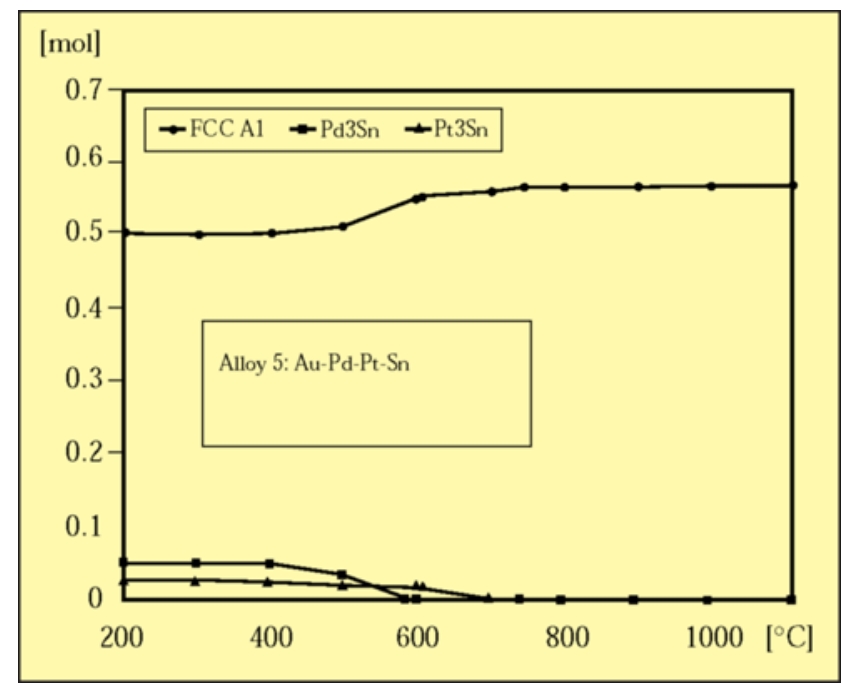

Figure 4e Calculated amounts of stable phases as a function of temperature for Alloy 5

more detailed investigation of ternary effects will be described in forthcoming papers $(8,9)$.

\section{CONCLUSIONS}

The comparison of experimental results with thermodynamic stability calculations shows good correlation for the gold alloys evaluated. The interpretation of the experimental results with the help of the calculations leads to a deeper understanding of the complex hardening mechanisms in these alloys and hence allows a reduction of the experimental work required to develop new alloy systems with specific properties.

\section{ACKNOWLEDGEMENT}

Discussions with Dr Philip Spencer, RWTH Aachen are gratefully acknowledged.

\section{ABOUT THE AUTHORS}

Dr Bernd Kempf is a scientist in the Research Department of Degussa's precious metals sector. $\mathrm{He}$ studied materials science in Erlangen and then moved to the Max-Planck Institut für Metallforschung in Stuttgart. He received his $\mathrm{PhD}$ for studies of the mechanical behaviour and failure mechanisms of high

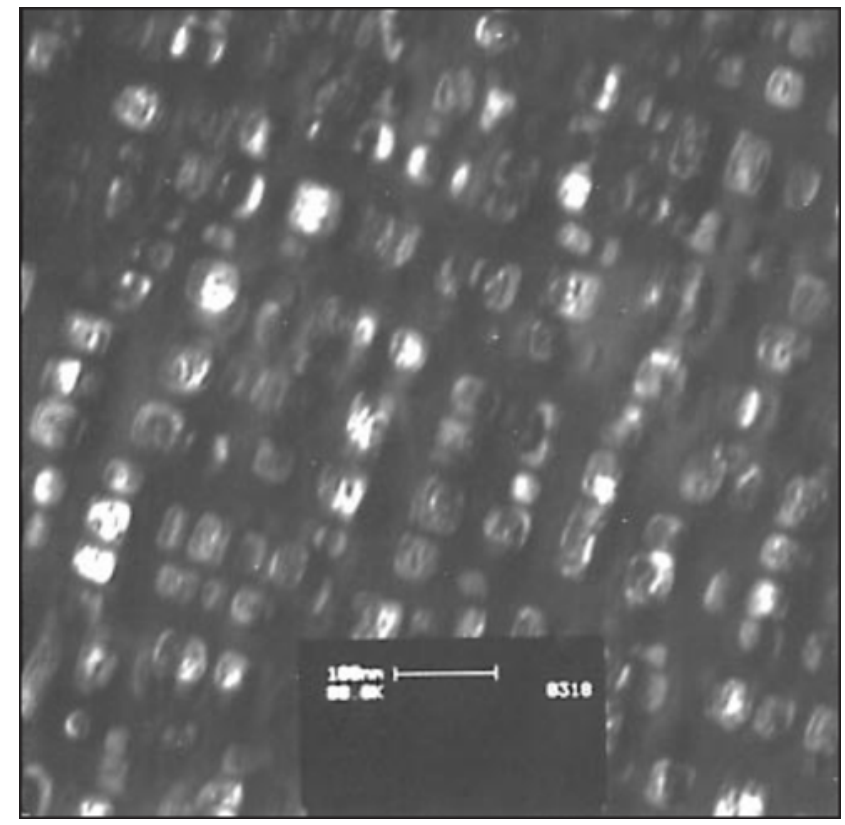

Figure 5 Dark field image of Alloy 2 after an age hardening process

temperature materials. In 1988 he moved to Degussa. His main activities in this Company are in the use of precious metal alloys for technical applications and for dental and jewellery materials.

Prof Dr Siegfried Schmauder has been employed at the Staatliche Materialprüfungsanstalt (MPA), University of Stuttgart, since 1994. He has studied Mathematics and Computer Science and received his $\mathrm{PhD}$ in Materials Science in the field of stimulating the mechanical behaviour of materials with complex microstructures at Max-Planck Institut für Metallforschung in Stuttgart in 1989. Since 1995 he has been head of the Department of Ceramics and Composites.

\section{REFERENCES}

1 E. Drost and J. Haußelt, Interdiscipl. Sci. Rev., 1992, 17, 271

2 B. Kempf and J. HauBelt, Interdiscipl. Sci. Rev, 1992, 17, 251

3 G. Erikson and K. Hack, Metall. Trans. B., 1990, 21B, 1013

4 P. Spencer and K. Hack, Swiss. Mater. 2, 1990, 69

5 B. Kempf, P. Spencer and J. Haußelt, Z. Metallk., 1995, 86, 603

6 M. Jeger, 'Einführung in die Kombinatorik', Band 1, Ernst Klett Verlag, Stuttgart, 1973

7 I. Stewart, Spektt: Wiss, 1996, 6, 14

8 A. Forstreuter, B. Kempf, T. Schober, S. Fries, W.A. Oates and H. Wenzl, submitted to Z. Metallk.

9 A. Kempf, A. Forstreuter and H. Wenzl, to be submitted to Gold Bullettin

10 T.B. Massaski, 'Binary Alloy Phase Diagrams', Vols. 1, 2 and 3, Second Edition, American Society of Metals, 1992 